http://jmscr.igmpublication.org/home/ ISSN (e)-2347-176x ISSN (p) 2455-0450 crossref DOI: https://dx.doi.org/10.18535/jmscr/v8i4.07

\title{
Treatment outcome of pulmonary tuberculosis patients attending a tertiary care centre
}

\author{
Authors
}

\author{
Dr Kulbir Singh ${ }^{1 *}$, Dr Parminder Pal Singh², Dr Bharat Bhushan ${ }^{3}$, \\ Dr Sudesh Kumari ${ }^{4}$, Dr Vinay Bhagat ${ }^{5}$, Dr Vicky Bakshi ${ }^{6}$ \\ ${ }^{1}$ Associate Professor, Department of Pulmonary Medicine, G.M.C. Patiala \\ ${ }^{2}$ Senior Resident, Department of Internal Medicine, G.M.C. Patiala \\ ${ }^{3}$ Professor, Department of Pulmonary Medicine, G.M.C. Patiala \\ ${ }^{4}$ Medical Officer, Department of Pulmonary Medicine, G.M.C. Patiala \\ ${ }^{5}$ Senior Resident, Department of Pulmonary Medicine, G.M.C. Patiala \\ ${ }^{6}$ Junior Resident, Department of Pulmonary Medicine, G.M.C. Patiala \\ *Corresponding Author \\ Dr Kulbir Singh \\ Associate Professor, Department of Pulmonary Medicine, GMC Patiala, India
}

\begin{abstract}
Tuberculosis [TB] has been a major cause of suffering and death since times immemorial. Thought to be one of the oldest human diseases, the history of TB is at least as old as the mankind. Since, the discovery of mycobacterium tuberculosis microscopic detection of the bacilli in clinical specimens has remained the mainstay of tuberculosis [TB] diagnosis in developing nations. This was a retrospective study, in which a total of 336 patients who were initiated on ATT on sputum AFB positive basis from Department of TB and Chest diseases, Government Medical College, Patiala from November 2009 to May 2010. The objective of this study was to find the treatment outcome in sputum AFB positive patients put on category I, II and III regimen of ATT under RNTCP \& to find the sputum conversion rate after 2 months in patients of pulmonary koch's put on category I, II and III regimen of ATT. These patients were followed up till end of their treatment and sputum for AFB was done at time of diagnosis, at the end of intensive phase of treatment and at the end of the treatment.Sputum AFB positive patients initiated on ATT were included in this study, while clinically diagnosed pulmonary tuberculosis patients and sputum AFB negative but Culture or CBNAAT positive patients were excluded. Our study showed low conversion rate and cure rates in both category I and category II patients. This may be due to the fact that patient may be having poor compliance but may also be due to lower efficacy of the alternate day regimen. More studies need to be done to evaluate the treatment outcome of DOTS in patients of sputum positive pulmonary tuberculosis. We also believe that proper patient follow up and education is needed to increase compliance to the anti tubercular drugs.
\end{abstract}

Keywords: Pulmonary Tuberculosis, Tertiary care centre, Treatment outcome, Sputum for AFB, Conversion rate.

\section{Introduction}

Worldwide, TB is one of the top 10 causes of death and the leading cause from a single infectious agent (above HIV/AIDS). Millions of people continue to fall sick with TB each year. ${ }^{1}$ India has more people with active TB than any other country in the world. Tuberculosis [TB] has been a major cause of suffering and death since 
times immemorial. Thought to be one of the oldest human diseases, the history of TB is at least as old as the mankind. Over the years, not only the medical implications but also the social and economic impact of TB has been enormous. On 24th March 1882 Koch announced the discovery of the tubercle bacillus during the monthly evening meeting of the Berlin Physiological Society. In 1884, he published a more comprehensive paper Die aetiologic der tuberculose in the second volume of the Reports of the Imperial Health Office. In 1905, he was awarded the Nobel Prize for his contributions in the field of TB research. ${ }^{2,3,4}$ Since, the discovery of mycobacterium tuberculosis microscopic detection of the bacilli in clinical specimens has remained the mainstay of tuberculosis [TB] diagnosis in developing nations. In pulmonary TB, sputum for AFB is the main diagnostic tool for diagnosis.

Microscopic detection of microbes in clinical specimens is the oldest approach to the laboratory diagnosis of infectious diseases, including TB. Microscopic detection of mycobacteria relies on the acid-fast nature of the organisms, resulting from the high lipid content of the mycobacterial cell wall. Two staining methods make use of this characteristic:

In the Ziehl-Neelsen (ZN) stain, carbol fuchsin enters the bacteria when heated but does not leave the cells when exposed to an alcohol/hydrochloric acid mixture. Mycobacteria are therefore seen as red-stained rods in a methylene blue-stained background. A modification of the $\mathrm{ZN}$ stain, the Kinyoun or cold stain, uses a higher concentration of phenol with the carbol fuchsin, and the slide does not need to be heated.

In the Auramine-O stain, carbol fuchsin is replaced by auramine. Auramine fluoresces when bound to DNA and viewed under a fluorescence microscope. After decolourization of non-acid-fast bacteria and other material, only the acid-fast bacilli fluoresce.

Nucleic acid amplification (NAA), now widely available, is among the newest diagnostic methods to take up the challenge of accurate and rapid detection and identification of MTBC (as well as NTM). Nucleic acid amplification tests (NAATs) serve to complement - not to replace - the conventional laboratory approach NAATs amplify M. tuberculosis (MTB)-specific nucleic acid sequences using a nucleic acid probe. These sequences are located on regions of difference between mycobacterial DNA. The most commonly used target sequences are IS6110 and a 16s rRNA, which are specific to the MTB. More recent targets have been developed specific for MTB itself ${ }^{5}$ NAATs enable direct detection of MTB in clinical specimens. NAATs require as few as 10 bacilli from a given sample under research conditions ${ }^{6}$ affording them a reasonable sensitivity for MTB to diagnosing active disease

\section{Methods}

This was a retrospective study, in which a total of 336 patients who were initiated on ATT on sputum AFB positive basis from Department of TB and Chest diseases, Government Medical College, Patiala from November 2009 to May 2010. Sputum for AFB was done at time of diagnosis, at the end of intensive phase of treatment and at the end of the treatment were noted.

\section{Inclusion Criteria}

1. Sputum AFB positive patients initiated on ATT

\section{Exclusion Criteria}

1. Clinically diagnosed pulmonary tuberculosis patients on ATT

2. Sputum AFB negative but Culture or CBNAAT positive patients

\section{Definitions}

Cured: Initially sputum smear-positive patient who has completed treatment and had negative sputum smears, on at least two occasions, one of which was at the end of treatment.

Treatment Completed: A sputum smear-positive patient who has completed treatment and had 
negative smears, at the end of Intensive Phase (IP), but none at the end of treatment.

Defaulted: A patient who has not taken anti-TB drugs for 2 months or more consecutively, after starting treatment.

Died: A patient who died during the course of treatment regardless of the cause of death.

Transferred out: A patient who has been transferred to another TB Unit or district and for whom the treatment result (outcome) is not known.

Favourable Treatment Outcome: Cured and treatment completed combined

\section{Results}

\section{Gender Distribution}

In our study, out of 336 patients, 222 (66\%) were male while 114 (34\%) were females. Out of 168 rural population, $52(31 \%)$ were female and 114 (69\%) were male. Out of 168 urban population, 62 $(37 \%)$ were females and $104(63 \%)$ were males. This may be attributed to less awareness and more social stigma among females, especially in rural conditions.

\section{Graph I}

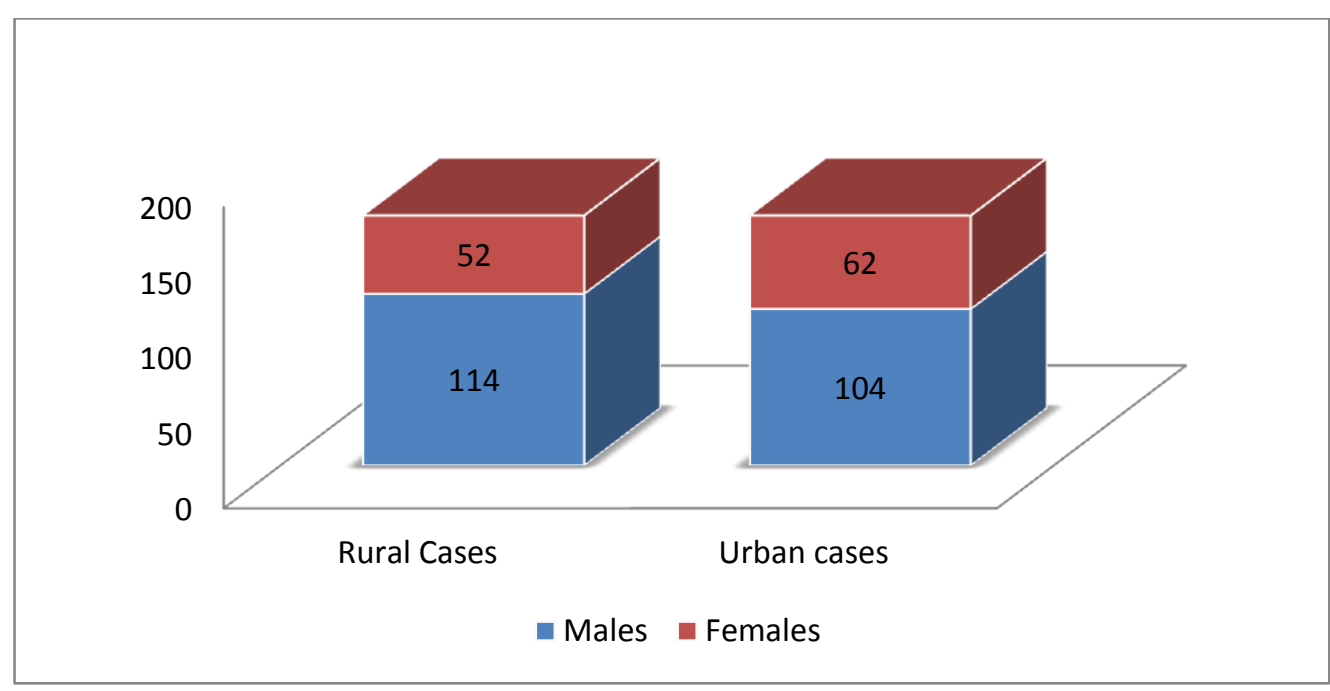

\section{Age Distribution}

In our study, youngest patient was of 8 yrs only while most elderly was a lady of 105 years.
Maximum patients ( 87 out of 336 ) were in the age group of 21 to 30 years, while no patient was there in age group 91 to 100 years.

\section{Graph II}

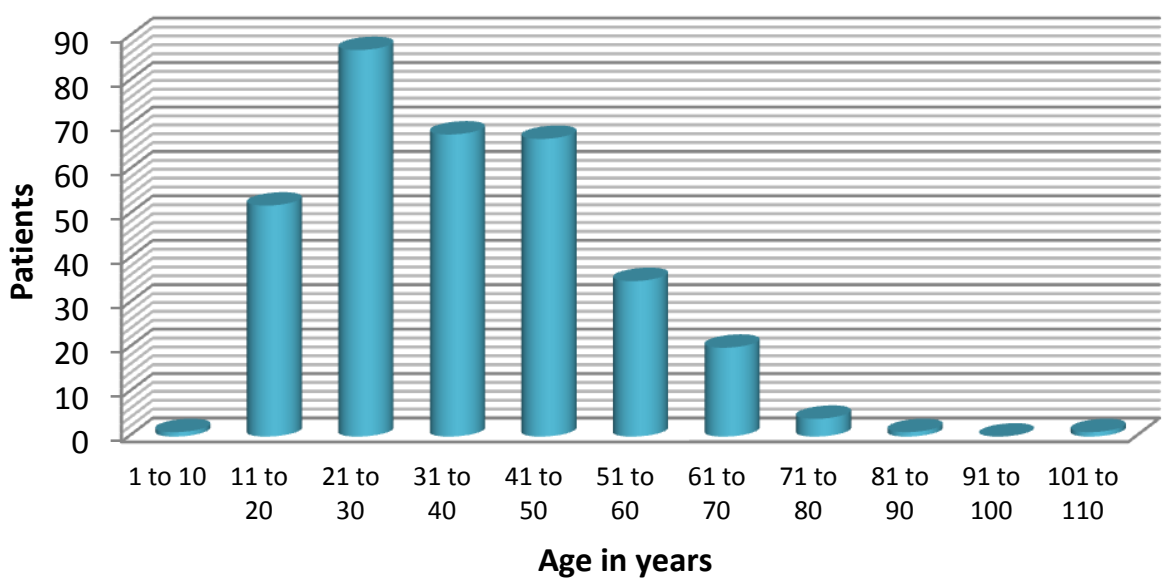

Patients 


\section{JMSCR Vol||08||Issue||04||Page 36-41||April}

\section{Category-wise Distribution}

Out of the 336 cases, 233 (69.3\%) patients were on Category 1, 102 (30.3\%) patients were on Category 2 and $1(0.3 \%)$ patient on Category 3.
$233(69.3 \%)$ patients were new sputum positive patients, $73(21.7 \%)$ were cases of treatment relapse, $29(8.6 \%)$ of treatment after default and a single $(0.3 \%)$ patient was of treatment failure.

\section{Chart I}

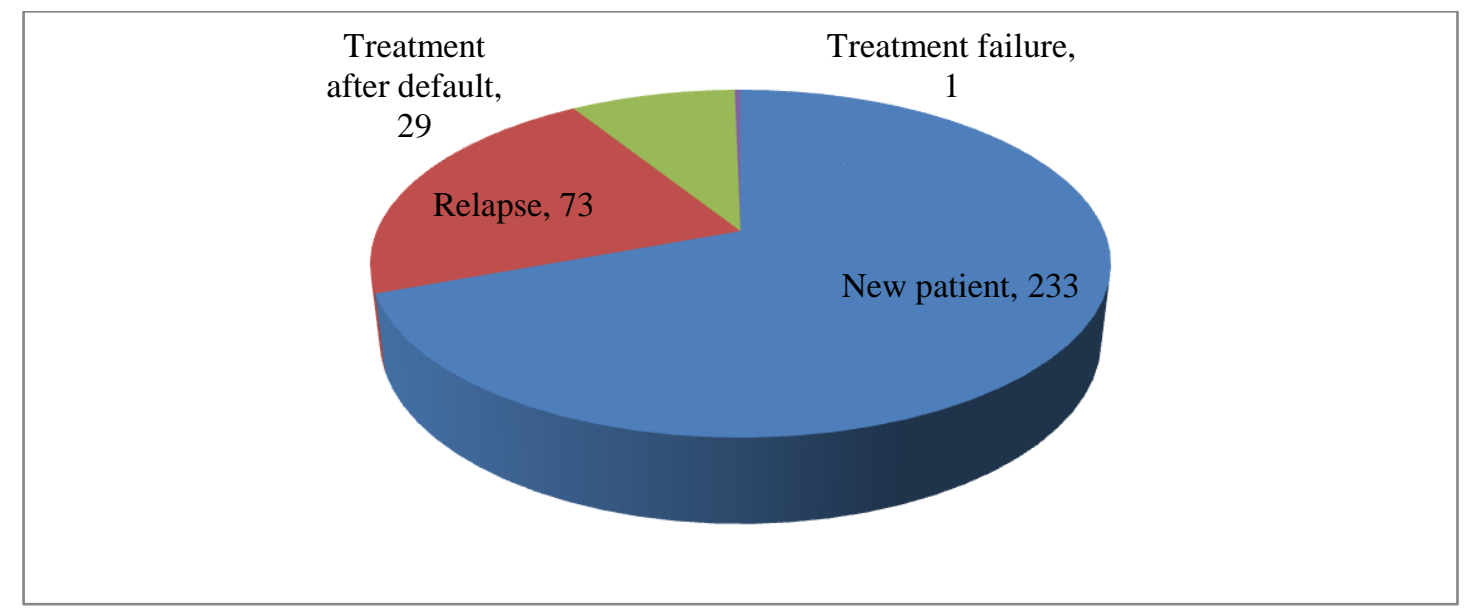

Table I

\begin{tabular}{lcccccc}
\hline Category & Total patients & Cured (\%) & $\begin{array}{c}\text { Treatment } \\
\text { Completed }\end{array}$ & Defaulted & Died & $\begin{array}{c}\text { Treatment } \\
\text { Failure }\end{array}$ \\
\hline I & 233 & $168(72.1)$ & $9(3.9 \%)$ & $11(4.7 \%)$ & $12(5.2 \%)$ & $6(2.6 \%)$ \\
II & 102 & $44(43.1)$ & $11(10.8 \%)$ & $8(7.8 \%)$ & $12(11.8 \%)$ & $2(2.0 \%)$ \\
III & 001 & $0(00.0)$ & $0(00.0)$ & $0(00.0)$ & $0(00.0)$ & $0(00.0)$ \\
\hline
\end{tabular}

\section{Sputum Grading}

Sputum for AFB was done for diagnosis of pulmonary tuberculosis, Scanty positive came in 7 patients, $1+$ in 151 patients, $2+$ in 77 patients and $3+$ in 103 patients.
End IP sputum positive cases were 37; 230 were negative and 99 patients data was not available. End of treatment, sputum positive cases were 3, sputum negative were 219 and in 114 patients data was unavailable.

Table II

\begin{tabular}{|c|c|c|c|c|c|c|}
\hline $\begin{array}{l}\text { Sputum } \\
\text { Grading }\end{array}$ & $\begin{array}{c}\text { Total } \\
\text { patients }\end{array}$ & Cured (\%) & $\begin{array}{c}\text { Treatment } \\
\text { Completed }(\%)\end{array}$ & Defaulted (\%) & Died (\%) & $\begin{array}{c}\text { Treatment } \\
\text { Failure (\%) }\end{array}$ \\
\hline Scanty & 5 & $1(20.0)$ & 0 & 0 & $1(20.0)$ & 0 \\
\hline $1+$ & 151 & $92(60.9)$ & $11(7.3)$ & $12(7.9)$ & $9(6.0)$ & $2(1.3)$ \\
\hline $2+$ & 77 & $50(64.9)$ & $5(6.5)$ & $3(3.9)$ & $4(5.2)$ & $3(3.9)$ \\
\hline $3+$ & 103 & $69(66.9)$ & $4(3.8)$ & $4(3.8)$ & $10(9.7)$ & $3(2.9)$ \\
\hline
\end{tabular}

\section{Sputum Conversion}

Sputum conversion after 2 months was $75.1 \%$ for Category I, $55 \%$ for Category II while 0 for
Category III patients. While Cure rate was $72.1 \%$ for Category I, $43.1 \%$ for Category II and 0 for Category III patients.

\section{Table III}

\begin{tabular}{lccc}
\hline Category & Total Patients & Sputum conversion at 2 mnths (\%) & Cured (\%) \\
\hline I & 233 & $175(75.1)$ & $168(72.1)$ \\
II & 102 & $55(53.9)$ & $44(43.1)$ \\
III & 1 & 0 & 0 \\
\hline
\end{tabular}

Hence, the sputum conversion rates were not in the line of National Tuberculosis Programmes accepted targets. 


\section{Treatment Outcome}

Treatment outcome was that $212(63 \%)$ patients were declared cured, $19(5.6 \%)$ patients defaulted, $8(2.3 \%)$ were of treatment failure, $24(7.1 \%)$ patients died, 51(15.2\%) patients were transferred out, $20(6 \%)$ patients were treatment completed, 1 (0.3\%) patient came to be MDR TB while for $1(0.3 \%)$ patient data was unavailable. Treatment outcome rates were also less.

\section{Chart II}

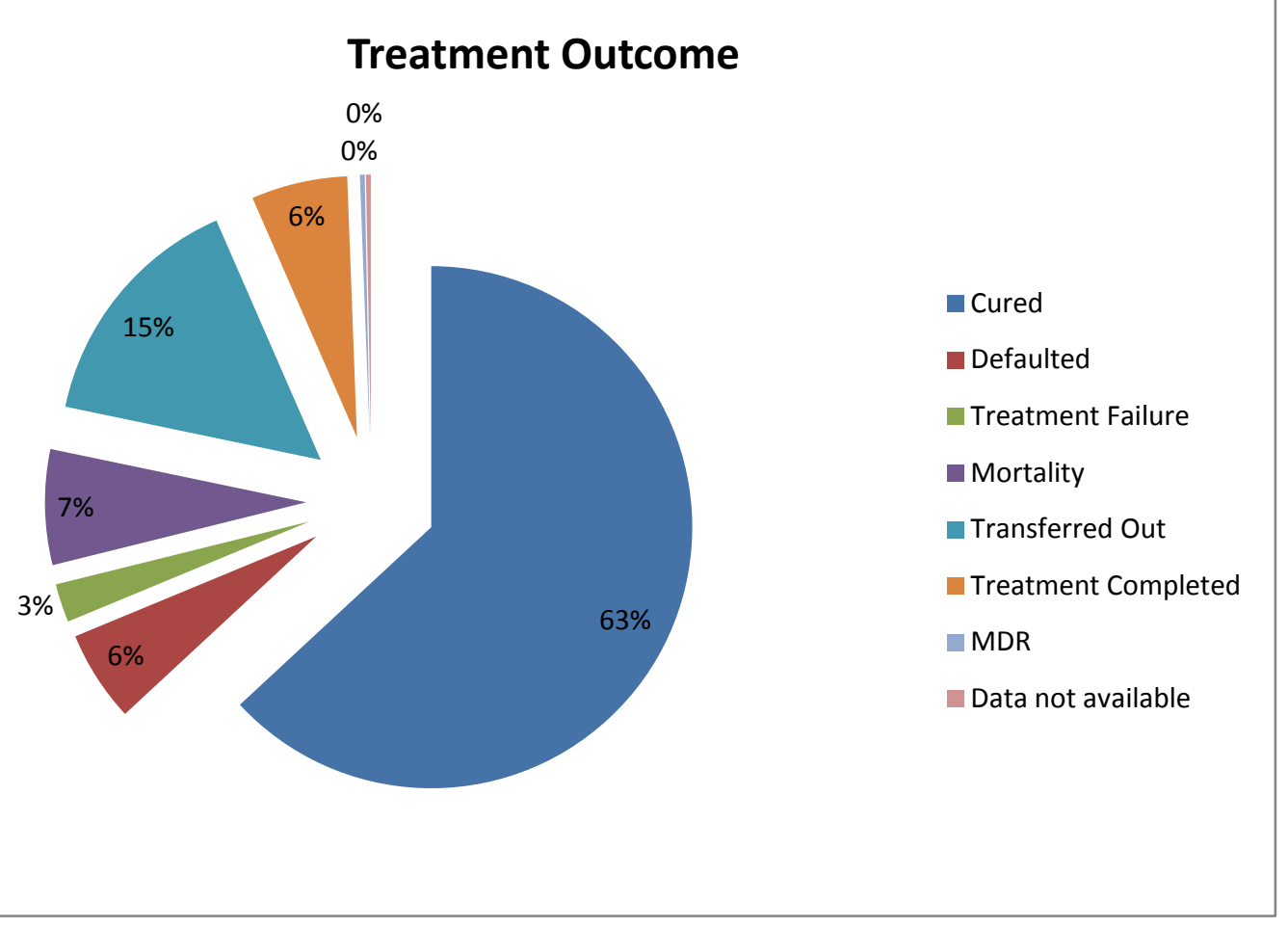

\section{Discussion}

In our study, out of 336 patients, 222 (66\%) were male while 114 (34\%) were females. While in a similar study conducted in Jagdalpur, Bastar ${ }^{7}$, $74 \%$ were males as compared to $26 \%$ females.

The cure rate for pulmonary tuberculosis was $63 \%$, while $5.6 \%$ patients defaulted, $2.3 \%$ were of treatment failure, $7.1 \%$ patients died, $15.2 \%$ patients were transferred out, $6 \%$ patients were treatment completed, $0.3 \%$ patient came to be MDR TB while for $0.3 \%$ patient data was unavailable.

In a similar study done in Aurungabad by Karanjekar $\mathrm{V}$ et $\mathrm{al}^{8}$ found that out of patients of pulmonary TB $41.1 \%, 38.3 \%$ and $15.9 \%$ were cured, treatment completed and defaulted respectively while $2.9 \%$ died.

The cure rate for patients of tuberculosis who took Category I ATT was $72.1 \%$, for Category II was $43.1 \%$ and zero cure rate in category 3 . Treatment completion rate were $3.9 \%, 10.8 \%$ and $0 \%$ for Category I,II and III respectively. Defaulters were $4.7 \%, 7.8 \%$ and zero for Category I, II and III respectively. Death rate was higher among Category II $(11.8 \%)$ followed by Category I $(5.2 \%)$ and none in Category III. 6(2.6\%) cases of treatment failure among category I and $2(2.0 \%)$ among category 2 were found.

Similar study done in Aurungabad, India by Karanjekar V et al ${ }^{8}$ found The Cure rate among Category I was $61.7 \%$ while it was $35 \%$ in Category II. No one in Category III was cured. Treatment completion rate was $16.7 \%, 30 \%$ and $75 \%$ among Category I, Category II, Category III patients respectively. Defaulters were $18.3 \%, 25 \%$ and 20\% among Category I, Category II and Category III respectively. Death rate was higher, i.e. 5\% among patients of Category II. No case of failure to treatment was observed in their study 
In this study Favourable treatment outcome was highest in Sputum grade 2+ at start of treatment (71.4\%), followed closely by sputum grading $3+$ $(70.7 \%)$ and $1+(68.2 \%)$. Least favourable treatment outcome was seen in sputum grade scanty for AFB at start of treatment (20\%). In a similar study done in Bastar 7, Favourable treatment outcome seen in Sputum grade 3+ $(85.5 \%)$, followed by $1+(80.2 \%), 2+(79.3 \%)$ and scanty $(71.4 \%)$. Hence both studies have similar inference that patients with scanty AFB sputum grading have low chances of favourable treatment outcome. This may be due to the fact that immunocompromised patients produce scanty bacilli in sputum and have lower chances of favourable treatment outcome.

Sputum conversion rate was only $75.1 \%$ for category I and a dismal $53.9 \%$ for patients on Category II, which is less than that of study done in Aurungabad ${ }^{8}$. This may be due to the poor compliance, lower literacy rate and poor follow up of patients in Punjab.

\section{Conclusion}

Our study shows low conversion rate and cure rates in both category I and category II patients. This may be due to the fact that patient may be having poor compliance but may also be due to lower efficacy of the alternate day regimen. More studies need to be done to evaluate the treatment outcome of DOTS in patients of sputum positive pulmonary tuberculosis.

We also believe that proper patient follow up and education is needed to increase compliance to the anti tubercular drugs.

\section{Bibliography}

1. WHO Global TB report 2018. Available at https://www.who.int/tb/publications/global _report/en/

2. Webb GB. Tuberculosis. New York: Hoeber; 1936.
3. Waksman SA. The conquest of tuberculosis. Berkeley and Los Angeles: University of California Press; 1964.

4. Rubin SA. Tuberculosis. The captain of all these men of death. Radiol Clin North Am 1995;33:619-39.

5. Soo PC, Horng YT, Hsueh PR, et al. Direct and simultaneous identification of Mycobacterium tuberculosis complex (MTBC) and Mycobacterium tuberculosis (MTB) by rapid multiplex nested PCRICT assay. J Microbiol Methods 2006;66(3): 440-448.

6. Diagnostic Standards and Classification of Tuberculosis in Adults and Children. This official statement of the American Thoracic Society and the Centers for Disease Control and Prevention was adopted by the ATS Board of Directors, July 1999. This statement was endorsed by the Council of the Infectious Disease Society of America, September 1999. Am J Respir Crit Care Med 2000;161 (4 Pt 1):1376-1395.

7. Kishor Parashramji Brahmapurkar, Vaishali K. Brahmapurkar, Sanjay P. Zodpey Sputum smear grading and treatment outcome among directly observed treatment-short course patients of tuberculosis unit, Jagdalpur, Bastar. J Family Med Prim Care. 2017 Apr-Jun; 6(2): 293-296.

8. Karanjekar V, Lokare P, Gaikwad A, Doibale M, Gujrathi V, Kulkarni A. Treatment outcome and follow-up of tuberculosis patients put on directly observed treatment short-course under rural health training center, Paithan, Aurangabad in India. Ann Med Health Sci Res. 2014;4:222-6. 